\title{
P-Selectin Targeted Dexamethasone-Loaded Lipid Nanoemulsions: A Novel Therapy to Reduce Vascular Inflammation
}

\author{
Viorel Simion, ${ }^{1}$ Cristina Ana Constantinescu, ${ }^{1,2}$ Daniela Stan, ${ }^{1}$ \\ Mariana Deleanu, ${ }^{1,3}$ Monica Madalina Tucureanu, ${ }^{1}$ Elena Butoi, ${ }^{1}$ Ileana Manduteanu, ${ }^{1}$ \\ Maya Simionescu, ${ }^{1}$ and Manuela Calin ${ }^{1}$ \\ ${ }^{1}$ Institute of Cellular Biology and Pathology "Nicolae Simionescu" of the Romanian Academy, Bucharest, Romania \\ ${ }^{2}$ Faculty of Veterinary Medicine, University of Agronomic Sciences and Veterinary Medicine, Bucharest, Romania \\ ${ }^{3}$ Faculty of Biotechnologies, University of Agronomic Sciences and Veterinary Medicine, Bucharest, Romania
}

Correspondence should be addressed to Manuela Calin; manuela.calin@icbp.ro

Received 12 May 2016; Revised 21 July 2016; Accepted 28 July 2016

Academic Editor: Mirella Giovarelli

Copyright (C) 2016 Viorel Simion et al. This is an open access article distributed under the Creative Commons Attribution License, which permits unrestricted use, distribution, and reproduction in any medium, provided the original work is properly cited.

\begin{abstract}
Inflammation is a common process associated with numerous vascular pathologies. We hypothesized that targeting the inflamed endothelium by coupling a peptide with high affinity for P-selectin to the surface of dexamethasone-loaded lipid nanoemulsions will highly increase their specific binding to activated endothelial cells (EC) and reduce the cell activation. We developed and characterized dexamethasone-loaded lipid nanoemulsions directed towards P-selectin (PLN-Dex) and monitored their antiinflammatory effects in vitro using cultured EC (EA.hy926 cells) and in vivo using a mouse model of acute inflammation [lipopolysaccharides (LPS) intravenously administered in C57BL/6 mice]. We found that PLN-Dex bound specifically to the surface of activated EC are efficiently internalized by EC and reduced the expression of proinflammatory genes, thus preventing the monocyte adhesion and transmigration to/through activated EC. Given intravenously in mice with acute inflammation, PLNDex accumulated at a significant high level in the lungs (compared to nontargeted nanoemulsions) and significantly reduced mRNA expression level of key proinflammatory cytokines such as IL-1 $\beta$, IL-6, and MCP-1. In conclusion, the newly developed nanoformulation, PLN-Dex, is functional in vitro and in vivo, reducing selectively the endothelium activation and the consequent monocyte infiltration and diminishing significantly the lungs' inflammation, in a mouse model of acute inflammation.
\end{abstract}

\section{Introduction}

The vascular endothelium constitutes a cell monolayer lining all the blood vessels and is considered to be the largest paracrine organ in the body [1]. Among many physiological functions performed by endothelial cells (EC) are the control of the vascular tone and the permeability of vessels and maintaining a nonthrombogenic and a nonadhesive surface for circulating blood cells $[2,3]$. Impairment of the EC functions is an early key step in the pathogenesis of numerous diseases, including cardiovascular, hematological, rheumatologic, renal, pulmonary, infectious, and oncological disorders [4-6].
Various pathological mediators including infectious agents, inflammatory molecules (cytokines/chemokines), reactive oxygen species, different antigens, or physical stress generate activation of EC, transduced by an increased expression of cell adhesion molecules. Thus, EC and their related surface-exposed cell adhesion molecules represent an attractive and accessible target for therapeutic intervention in a myriad of inflammatory diseases.

A potential molecular target of $\mathrm{EC}$ is $\mathrm{P}$-selectin $(\mathrm{CD} 62 \mathrm{P})$, an inducible cell adhesion molecule overexpressed on the surface of activated endothelium in pathologically altered vasculature [7]. P-Selectin is located on the membrane of secretory granules of platelets and endothelial cells [8] and 
upon cell stimulation with thrombin, histamine, or other molecules, it is redistributed to the plasma membrane where it mediates the leukocytes recruitment [9]. The protein is quickly internalized from the surface of activated EC and returns to the trans-Golgi network, from where it is sorted to secretory granules [10]. The finding that P-selectin is an internalizing receptor [11] stands for its suitability as appropriate target for intracellular delivery of therapeutic drugs into EC.

Previous studies showed the feasibility of using P-selectin as a therapeutic target in preclinical studies for different inflammatory pathologies. Thus, the administration of a Pselectin recombinant ligand (rPSGL-Ig) reduced the neointimal hyperplasia after balloon injury, by inhibiting the inflammatory and thrombotic responses in porcine coronary arteries [12]. The same group has tested the P-selectin recombinant ligand in a Zucker diabetic rat model reporting that a single intravenous injection suppressed inflammation and inhibited CD45-positive leukocytes infiltration and neointimal formation after arterial injury [13]. In a different study, administration of oligosaccharides targeted to Pand L-selectin inhibited the influx of neutrophils into the peritoneal cavities of an acute inflammation mouse model [14]. Similarly, infusion of sialyl-Lewis X, a P-selectin ligand, significantly decreased lung injury and neutrophils accumulation in the tissue, while the irrelevant oligosaccharides had no significant effects [15].

A gold standard medicine for anti-inflammatory therapy is dexamethasone, a potent glucocorticoid used in the treatment of immune-mediated inflammatory diseases that effectively inhibits the expression of many inflammatory mediators like cytokines/chemokines: tumor necrosis factor$\alpha$ (TNF- $\alpha$ ), interleukin-1 beta (IL-1 $\beta$ ), IL-2, and IL-6 [16]. Dexamethasone has a complex mechanism of action involving interaction with diverse targets in both the cytosol and nucleus. Similar to the natural glucocorticoid hormone cortisol, the dexamethasone binds to the cytosolic glucocorticoid receptor (GR), initiating its translocation into the nucleus where it binds to specific DNA responsive elements and activates gene transcription. Alternatively, the GR can complex other transcription factors in the cytosol, like NF$\kappa \mathrm{B}$ or $\mathrm{AP}-1$, preventing their translocation in the nucleus and inhibiting the expression of proinflammatory molecules [17].

We can safely assume that improving dexamethasone delivery into EC may lead to more potent and specific effects. However, systemically administered dexamethasone does not have an affinity for the activated endothelium and generates several unwanted serious side effects in healthy cells and tissues such as immunosuppression, metabolic alterations, osteoporosis, gastrointestinal bleeding and ulcer, hypertension, hyperglycemia, and adrenal insufficiency [18]. Hence, long term administration is not an option and, currently, corticosteroids are used especially as a bridging therapy for the acute stage of chronic conditions such as rheumatoid arthritis [19].

As a strategy to provide targeted delivery to the endothelium, drugs or their carriers can be conjugated with ligands that have affinity for endothelial surface determinants. Different surface-exposed proteins, specifically upregulated on the surface of activated EC (i.e., E-selectin, ICAM-1, and VCAM1) were employed to target dexamethasone to endothelium using delivery vehicles functionalized with specific ligands, with the purpose of modulating the inflammatory process $[20,21]$. Dexamethasone-loaded liposomes functionalized with RGD peptide accumulates in LPS-induced inflammatory sites and provides protective effects that are superior to nontargeted dexamethasone-loaded liposomes in a rat arthritis model [22]. In a glomerular inflammation mouse model, dexamethasone-loaded liposomes coated with E-selectin antibody exhibit an $~ 4$-fold higher uptake in inflamed kidneys versus nontargeted liposomes and reduce the inflammatory markers by $60-70 \%$ relative to controls [23]. Functionalization of dexamethasone-loaded dextran nanogels with ICAM-1 recognizing antibody increased their lung accumulation in LPS-induced endotoxemia mice model and blocked the overexpression of proinflammatory molecules VCAM-1 and ICAM-1 in lungs lysates [21].

In an attempt to increase the specificity of dexamethasone for EC, in this study, we tested whether lipid nanoemulsions encapsulating dexamethasone and directed specifically towards activated EA.hy926 cells (a human endotheliumderived permanent cell line) exposed P-selectin reduce the inflammatory process. We designed lipid nanoemulsions (LN) that encapsulate with high efficiency the hydrophobic drug dexamethasone (LN-Dex) and coupled a peptide with high affinity for P-selectin (previously described in [24]) on the surface of LN-Dex (PLN-Dex). We report here that PLN-Dex, upon binding and internalization by cultured EA.hy926 cells, reduced the expression of several proinflammatory molecules and decreased the monocytes adhesion and transmigration across cells. In a mouse model of inflammation, administered PLN-Dex accumulates with high affinity in the lungs, where it is reducing significantly the level of proinflammatory molecules, IL-1 $\beta$, MCP-1, and IL-8. To our knowledge, this is the first study showing that P-selectin-directed lipid nanoemulsions can be used for selective delivery of anti-inflammatory drugs to sites with activated endothelial cells.

\section{Materials and Methods}

2.1. Reagents. Reagents were obtained from the following sources: dexamethasone, soybean oil, glycerin, dialysis bag (cut-off size $10 \mathrm{kDa}$ ), 3-[4,5-dimethylthiazol-2-yl]-2,5diphenyltetrazolium bromide, dexamethasone, lipopolysaccharides from Escherichia coli serotype O111:B4, and recombinant tumor necrosis factor-alpha (TNF- $\alpha$ ) from SigmaAldrich Chemie (Germany); spectra/Por dialysis bag (cut-off of 500-1000 Da) from Spectrum Labs (Spectrum Europe BV, Breda, Netherlands); egg phosphatidylcholine (EPC), 1,2distearoyl-sn-glycero-3-phosphoethanolamine-N-[maleimide(polyethylene glycol)-2000] (Mal-PEG-DSPE), 1,2-dipalmitoyl-sn-glycero-3-phosphoethanolamine-N-(lissamine Rhodamine B sulfonyl) (ammonium salt) (Rhodamine-PE), and 1,2-distearoyl-sn-glycero-3-phosphoethanolamine$\mathrm{N}$-[amino(polyethylene glycol)-2000] (PEG-DSPE) from Avanti Polar Lipids (Alabaster, AL/USA); and Dulbecco's modified Eagle's medium (DMEM), RPMI medium, foetal 
calf serum (FCS), penicillin G, and streptomycin from Gibco BRL (Gaithersburg, MD/USA); the cell culture plates were supplied by Corning (New York, NY/USA); transmigration chambers were from Costar Europe Ltd. (Badhoevedorp, Netherlands). Tris(2-carboxyethyl) phosphine (TCEP) was purchased from Thermo Scientific (Massachusetts, USA); $2^{\prime} 7^{\prime}$-bis(2-carboxyethyl)-5(6)-carboxyfluorescein acetoxymethyl ester (BCECF-AM) was from Life Technologies (Carlsbad, CA, USA); Amicon centrifugal filter columns with a cut-off of $100 \mathrm{kDa}$ were from Millipore. The peptide with high affinity for P-selectin (CGGSSLVSVLDLEPLDAAWL) was synthesized by GeneCust (Dudelange, Luxembourg). Deionized $(18.2 \mathrm{M} \Omega / \mathrm{cm})$ water was generated in-house using a Milli-Q system from Millipore.

\subsection{Preparation of Dexamethasone-Loaded Lipid Nanoemul-} sions (LN-Dex). The LN-Dex were prepared employing the ultrasonication method as previously described [25]. Briefly, the organic and the aqueous phase were prepared separately. The organic phase, composed of EPC (10 mM), phospholipidic derivatives of PEG (PEG-DSPE $(150 \mu \mathrm{M})$ and Mal-PEGDSPE $(200 \mu \mathrm{M}))$, soybean oil $(50 \mu \mathrm{L})$, and dexamethasone (Dex) $(250 \mu \mathrm{g})$ dissolved in chloroform, was evaporated using a vacuum rotary evaporator. The aqueous phase containing $1 \mathrm{~mL}$ of double distilled water and glycerin $(100 \mu \mathrm{L})$ was added to the organic phase and sonicated for $5 \mathrm{~min}$ in a water bath, at $40 \mathrm{~V}$ intensity using a UP200H probe-type sonicator (Heidolph). The lipid nanoemulsions (LN) obtained were further centrifuged using Amicon centrifugal filter units of $100 \mathrm{kDa}$ in order to separate the Dex-entrapped nanoemulsions from free (nonentrapped) Dex and to eliminate any traces of the organic solvent. As control, LN without dexamethasone were produced. For microscopy studies, the LN were fluorescently labeled with Rhodamine-PE added at a $1 \mathrm{~mol} \%$ ratio.

\subsection{Coupling of P-Selectin Recognizing Peptide to Lipid} Nanoemulsions (PLN). The P-selectin binding peptide, with the sequence CGGSSLVSVLDLEPLDAAWL, containing the amino acid cysteine followed by a linker formed by the amino acids GGSS and the sequence LVSVLDLEPLDAAWL [24] was coupled with the maleimide group at the distal end of PEG (Mal-PEG-DSPE) by sulfhydryl-maleimide interactions, as previously described [26]. Before coupling, the peptide was activated by adding a reducing agent (TCEP buffer) to break the disulfide bonds and mixed for 2 hours at room temperature. The excess TCEP was removed by dialysis (using cellulose ester membrane with a cut-off of 500$1000 \mathrm{Da})$, overnight at $4^{\circ} \mathrm{C}$ against coupling buffer $(10 \mathrm{mM}$ $\mathrm{Na}_{2} \mathrm{HPO}_{4}, 10 \mathrm{mM} \mathrm{NaH} \mathrm{PO}_{4}, 2 \mathrm{mM}$ EDTA, $30 \mathrm{mM}$, and $\mathrm{pH}$ : 6.7). Then, the peptide was added (at molar ratio of $2: 1$, peptide : maleimide-PEG-DSPE) to LN or LN-Dex suspensions and mixed together at room temperature for 6 hours. After this, to saturate the uncoupled maleimide groups, Lcysteine $(1 \mathrm{mM})$ was added for $30 \mathrm{~min}$. As a purification step, the mixture was centrifuged using Amicon centrifugal filter units of $100 \mathrm{kDa}$ in order to separate the nanoemulsions from uncoupled peptide, L-cysteine, and free (nonentrapped) Dex. At this step, the excess glycerin was either filtrated or retained by the ultrafiltration membrane [27]. The size of the lipid nanoemulsions was determined by photon correlation spectroscopy using Nicomp submicron particle analyzer model 380 (Nicomp Inst. Corp., Santa Barbara, CA, USA) and the multimodal distribution as previously described [25]. The amount of peptide coupled at the surface of LN was quantified by HPLC employing a UHPLC-Agilent 1290 Infinity with a Zorbax Eclipse Plus C18 column $(2.1 \times 100 \mathrm{~mm}, 3.5 \mu \mathrm{m})$. The mobile phase consisted of a gradient of $0.1 \%$ TFA in water (A) and $0.1 \%$ TFA in acetonitrile (B) $(60 \% \mathrm{~A}$ and $40 \% \mathrm{~B}$ until minute 7 when the proportion was inversed at $40 \% \mathrm{~A}$ and $60 \% \mathrm{~B}$ and then switched again at $60 \% \mathrm{~A}$ and $40 \% \mathrm{~B}$ at minute 9). The flow rate was $0.25 \mathrm{~mL} / \mathrm{min}$ and the detector wavelength was set at $220 \mathrm{~nm}$. The amount of coupled peptide was determined indirectly by measuring the amount of uncoupled, free peptide as previously described [28]. The amount of entrapped dexamethasone was determined by UHPLC-Agilent 1290 Infinity with a column Zorbax Eclipse Plus C18 $(2.1 \times 100 \mathrm{~mm}, 3.5 \mu \mathrm{m})$. The mobile phase was a mixture (at a ratio of $50: 50$ ) consisting of $10 \mathrm{mM} \mathrm{NaH}_{2} \mathrm{PO}_{4}$, $\mathrm{pH}$ : 3, and acetonitrile. Dexamethasone was detected at $242 \mathrm{~nm}$ using a flow rate of $0.25 \mathrm{~mL} / \mathrm{min}$.

2.4. Cell Culture. Human endothelial cell line (EA.hy926 cell line) (purchased from American Type Culture Collection) was grown to confluence in Dulbecco's modified Eagle's medium (DMEM) supplemented with $10 \%$ foetal calf serum, $100 \mathrm{U}$ penicillin, and $100 \mu \mathrm{g}$ streptomycin $/ \mathrm{mL}$, at $37^{\circ} \mathrm{C}$ in a $5 \%$ $\mathrm{CO}_{2}$ incubator using Petri dishes $(60 \mathrm{~mm}$ diam) or 24-well plates (with a density of $4 \times 10^{4}$ cells/well). Characterization of the cultured EA.hy926 cells showed that they express the typical EC feature: morphologically, they appeared as a monolayer of closely apposed polygonal-shape cells and expressed von Willebrand factor [29].

THP-1 cells, a monocyte cell line (a kind gift of Professor Dimitris Kardassis, University of Crete Medical School, Heraklion, Greece) were grown in suspension in RPMI 1640 culture medium containing $5 \%$ inactivated foetal calf serum, at $37^{\circ} \mathrm{C}, 5 \% \mathrm{CO}_{2}$, and were split up $(1: 5)$ twice a week [30].

2.4.1. Visualization of PLN Binding and Internalization by EA.hy926 Cells Using Confocal Microscopy. To this purpose, the EA.hy926 cells were seeded on coverslips in 24-well plates in complete growth medium at a density of $7 \times 10^{4}$ cells/well for 24 hours and, then, to increase the surface expression of $\mathrm{P}$ selectin, the cells were activated with TNF- $\alpha(20 \mathrm{ng} / \mathrm{mL})$ for 18 hours.

For binding studies, EA.hy926 cells were slightly fixed with $4 \%$ paraformaldehyde (PFA) and then incubated for 1 hour with a suspension of Rhodamine-PE labeled PLN or LN (as control). After washing, the cells were mounted with Roti-Mount FluorCare DAPI (ROTH GmBH, Germany) on microscope slides.

For internalization studies, activated EA.hy926 cells were incubated with a suspension of fluorescently labeled PLN and nontargeted LN for different time intervals $(30 \mathrm{~min}$, 2 , 4 , or 8 hours), washed with PBS, and then fixed with $4 \%$ paraformaldehyde and mounted on slides, as described above. The microscope slides were visualized using a confocal 
TABLE 1: The sequence of primers used for real-time PCR experiments to detect the mRNA levels of specified genes in human cells.

\begin{tabular}{|c|c|c|c|}
\hline Number & Gene & Sense & Sequence $5^{\prime}-3^{\prime}$ \\
\hline \multirow{2}{*}{1} & \multirow{2}{*}{ Human IL-1 $\beta$} & Forward & TGG CCCTAAACA GATGAAGTGC \\
\hline & & Reverse & TCAACACGCAGGACAGGTACAG \\
\hline \multirow{2}{*}{2} & \multirow{2}{*}{ Human TNF- $\alpha$} & Forward & TTCCTCAGCCTCTTCTCCTTC C \\
\hline & & Reverse & TGATGGCAGAGAGGAGGTTGAC \\
\hline \multirow{2}{*}{3} & \multirow{2}{*}{ Human IL-6 } & Forward & CCTGAACCTTCCAAAGATGGC \\
\hline & & Reverse & TTCACCAGGCAAGTCTCCTCA \\
\hline \multirow{2}{*}{4} & \multirow{2}{*}{ Human MCP-1 } & Forward & CAGCCAGATGCAATCAATGCC \\
\hline & & Reverse & TGGAATCCTGAACCCACTTCT \\
\hline \multirow{2}{*}{5} & \multirow{2}{*}{ Human IL-8 } & Forward & ACTGAGAGTGATTGAGAGTGGAC \\
\hline & & Reverse & AACCCTCTGCACCCAGTTTTC \\
\hline \multirow{2}{*}{6} & \multirow{2}{*}{ Human RANTES } & Forward & CCAGCAGTCGTCTTTGTCAC \\
\hline & & Reverse & CTCTGGGTTGGCACACACTT \\
\hline
\end{tabular}

laser scanning inverted microscope (Leica TCS SP5) using $560 \pm 20 \mathrm{~nm}$ excitation and $585 \pm 25 \mathrm{~nm}$ emission wavelengths for Rhodamine and $390 \pm 20 \mathrm{~nm}$ excitation and $470 \pm 20 \mathrm{~nm}$ emission wavelengths for DAPI-stained nuclei. The images were processed using LAS AF software (version 2.6).

2.4.2. Quantitative Determination of PLN Binding and Uptake with EA.hy926 Cells Using Flow Cytometry. To quantify the global cellular association (binding and uptake) of PLN, the activated EC were seeded onto 12 -well plates for 24 hours, activated with TNF- $\alpha(20 \mathrm{ng} / \mathrm{mL})$ for 18 hours, and then incubated with Rhodamine-labeled PLN and LN for 2 hours. To investigate the specificity of PLN association by activated EA.hy926 cells, competitive studies were performed. The cells were preincubated for 1 hour with an excess of P-selectin binding peptide ( 25 -fold higher concentration of peptide as compared to peptide coupled to the PLN surface) before incubation with PLN. After washing three times with PBS, the cultured EA.hy926 cells were detached from the dishes using 5 mM EDTA, washed with PBS, pelleted, and analyzed with a Gallios Flow Cytometer (Beckman Coulter), using blue laser excitation at $488 \mathrm{~nm}$ and emission at 585/42 $\mathrm{nm}$ in the FL2-H channel.

2.4.3. RNA Isolation, Reverse-Transcription, and Real-Time PCR. EA.hy926 cells were seeded at a concentration of 400.000 cells/well in 6-well plates, allowed to grow for 24 hours, and then incubated for 8 hours with TNF- $\alpha$ (20 $\mathrm{ng} / \mathrm{mL}$ ) and $1 \mu \mathrm{M}$ Dex either free or encapsulated into PLN (PLN-Dex) or LN (LN-Dex) or with control PLN (without Dex). Total cellular RNA was isolated using TRIzol reagent. First-strand cDNA synthesis was performed employing $1 \mu \mathrm{g}$ of total RNA and MMLV reverse transcriptase according to the manufacturer's protocol (Invitrogen). Quantification of mRNA was performed after amplification of cDNA using a LightCycler 480 Real-Time PCR System (Roche), SYBR Green I chemistry, and primers reported in Table 1 for human genes and in Table 2 for mouse genes. The optimized amplification conditions were $2.5 \mathrm{mM} \mathrm{MgCl}_{2}$, annealing at $60^{\circ} \mathrm{C}$, and extension at $72^{\circ} \mathrm{C}$ for 40 cycles. The relative quantification was done using the comparative $C_{T}$ method and expressed as arbitrary units. The mRNA levels were normalized to $\beta$-actin mRNA level.

2.4.4. Monocytes Adhesion Assay. Confluent cultured EA.hy926 cells (in 24-well plates) were coincubated with TNF- $\alpha(20 \mathrm{ng} / \mathrm{mL})$ and $1 \mu \mathrm{M}$ Dex either free or encapsulated into PLN-Dex or LN-Dex or with control PLN (without Dex) for 8 hours. Monocytes (THP-1 cells) were fluorescently labeled by incubation with $10 \mu \mathrm{M} 2^{\prime} 7^{\prime}$-bis(2-carboxyethyl)5(6)-carboxyfluorescein acetoxymethyl ester (BCECF-AM) for 30 minutes at $37^{\circ} \mathrm{C}$ in RPMI 1640 culture medium and subsequently washed by centrifugation.

The EA.hy926 cells were washed (three times) with warm PBS and then incubated with fluorescently labeled monocytes $\left(10^{6}\right.$ cells $\left./ \mathrm{mL}\right)$ for 30 minutes at $37^{\circ} \mathrm{C}$. Nonadherent monocytes were removed by washing with warm PBS and the cells (EA.hy926 cells and adherent monocytes) were lysed with lysis buffer and analyzed by a TECAN Spectrophotometer with the excitation and emission wavelengths of $480 \mathrm{~nm}$ and $520 \mathrm{~nm}$, respectively.

2.4.5. Monocytes Transmigration Assay. The effect of PLNDex on transmigration of human monocytes through activated EA.hy926 cells was assessed by classical transmigration assay using Boyden chambers. The EA.hy926 cells were seeded on the insert's filter pretreated with $0.1 \%$ gelatin and at confluency they were exposed for $6 \mathrm{~h}$ to $20 \mathrm{ng} / \mathrm{mL}$ TNF$\alpha$ and $1 \mu \mathrm{M}$ Dex either free or encapsulated into PLN or LN (PLN-Dex and LN-Dex, resp.) or with control PLN/LN (without Dex). Monocytes were labeled with BCECF-AM and incubated with the EA.hy926 cells monolayer for $16 \mathrm{~h}$. Transmigration of monocytes was assessed using a serum gradient (1\% FCS in the upper chamber and 10\% FCS in the lower chamber). The monocytes migrating in the lower chamber as well as those adhered on the lower part of the filter were trypsinized and washed with PBS and the fluorescence was measured using a TECAN Spectrophotometer with the excitation and emission wavelengths of $480 \mathrm{~nm}$ and $520 \mathrm{~nm}$, respectively. 
TABLE 2: The sequence of primers used for real-time PCR experiments to detect the mRNA levels of specified genes in mice organ homogenates.

\begin{tabular}{|c|c|c|c|}
\hline Number & Gene & Sense & Sequence $5^{\prime}-3^{\prime}$ \\
\hline \multirow{2}{*}{1} & \multirow{2}{*}{ Mouse IL-1 $\beta$} & Forward & GAAATGCCACCTTTTGACAGTG \\
\hline & & Reverse & TGGATGCTCTCATCAGGACAG \\
\hline \multirow{2}{*}{2} & \multirow{2}{*}{ Mouse TNF- $\alpha$} & Forward & CCTGTAGCCCACGTCGTAG \\
\hline & & Reverse & GGGAGTAGACAAGGTACAACCC \\
\hline \multirow{2}{*}{3} & \multirow{2}{*}{ Mouse IL-6 } & Forward & CTGCAAGAGACTTCCATCCAG \\
\hline & & Reverse & AGTGGTATAGACAGGTCTGTTGG \\
\hline \multirow{2}{*}{4} & \multirow{2}{*}{ Mouse MCP-1 } & Forward & TAAAAACCTGGATCGGAACCAAA \\
\hline & & Reverse & GCATTAGCTTCAGATTTACGGGT \\
\hline
\end{tabular}

\subsection{Animal Studies}

2.5.1. The Animal Model. For this study, male C57BL/6 mice from Charles River Laboratories were used. All animals had access to standard rodent diet and water ad libitum and were kept in a temperature-controlled chamber at $24^{\circ} \mathrm{C}$ with a 12-hour light/dark cycle. The inflammation was induced in C57BL/6 mice by intravenous injection of lipopolysaccharides from Escherichia coli serotype O111:B4 at a concentration of $0.5 \mathrm{mg} / \mathrm{kg}$. Care was taken to avoid animal suffering at each stage of experiment.

2.5.2. Determination of Uptake of Fluorescently Labeled PLN or LN by Ex Vivo Imaging. The mice (20-25 grams of weight) were given intravenously (i.v.) the sterile PBS or LPS $(0.5 \mathrm{mg} / \mathrm{kg})$ and after 4 hours injected with $100 \mu \mathrm{L}$ ( $1 \mu$ mol lipids) of Rhodamine-labeled PLN or LN. Five hours after the LPS injection, the animals were anesthetized with ketamine/xylazine, exsanguinated via open heart puncture, and perfused with cold PBS through the left ventricle while the liver was punctured to allow exclusion of the systemic blood. The heart, lung, liver, spleen, kidney, and the brain were harvested and their fluorescence was analyzed by an imaging system IVIS Spectrum Caliper $(560 \mathrm{~nm}$ excitation wavelength, $590 \mathrm{~nm}$ emission wavelength). The images were quantified for fluorescent radiant efficiency [fluorescence emission radiance per incident excitation intensity: $\left.\left(\mathrm{p} / \mathrm{sec} / \mathrm{cm}^{2} / \mathrm{sr}\right) /\left(\mu \mathrm{W} / \mathrm{cm}^{2}\right)\right]$ using region-of-interest (ROI) function of Living Image 4.3.1. software. Then, the tissues were frozen in liquid nitrogen and stored at $-80^{\circ} \mathrm{C}$ until further assays. Tissue homogenates were obtained utilizing a Silent Crusher M homogenizer from Heidolph.

2.5.3. Assessment of the Effect of PLN-Dex Administration on the Expression of Inflammatory Molecules. Mice were given i.v. LPS $(0.5 \mathrm{mg} / \mathrm{kg})$ and $100 \mu \mathrm{L}$ of free dexamethasone $(1 \mathrm{mg} / \mathrm{kg}$, Dex $)$ or Dex encapsulated in lipid nanoemulsions [PLN-Dex $(0.5 \mathrm{mg} / \mathrm{kg}$ dexamethasone), LN-Dex $(0.5 \mathrm{mg} / \mathrm{kg}$ dexamethasone)] or empty PLN. After 3 hours, similar concentrations of free dexamethasone or nanoemulsions were reinjected into the mice. At 24 hours after the first i.v. administration, the animals were anesthetized, exsanguinated via open heart puncture, and perfused with cold PBS through the left ventricle while the liver was punctured to allow exclusion of the systemic blood. The heart, lung, liver, spleen, kidney, and the brain were harvested, frozen in liquid nitrogen, and stored at $-80^{\circ} \mathrm{C}$ until further assays. Tissue homogenates were obtained utilizing a Silent Crusher M homogenizer from Heidolph. RT-PCR for inflammatory molecules (IL-1 $\beta$, TNF- $\alpha$, IL- 6 , and MCP-1) was performed as described in the previous section. The primers used are indicated in Table 2.

2.6. Statistical Analysis. The results were expressed as mean \pm $\mathrm{SD}$ and experiments were performed at least in triplicate. The animal studies included three to seven mice/group. Statistical differences were evaluated using Kruskal-Wallis nonparametric independent analysis, followed by Bonferroni, DunnSidak, and Tukey post hoc tests. Differences were considered to be statistically significant at a level of $p<0.05$.

\section{Results}

3.1. Characterization of Lipid Nanoemulsions. The lipid nanoemulsions employed in this study were obtained by a method developed and characterized in a previous study [25]. The physicochemical characterization by dynamic light scattering revealed that the size of the LN-Dex and PLNDex was $132 \pm 1.4 \mathrm{~nm}$ and $143 \pm 2.6 \mathrm{~nm}$, respectively, with a polydispersity index between 0.083 and 0.13 . HPLC data indicated that the peptide with specificity for P-selectin is coupled at the surface of lipid nanoemulsions at a concentration of $32 \pm 3 \mu \mathrm{g}$ peptide/ $\mu \mathrm{mol}$ total lipids (equivalent of $82 \pm 3 \%$ of the total peptide incubated with LN). The entrapment efficiency of dexamethasone into lipid nanoemulsions determined by HPLC is $90 \pm 2 \%$, corresponding to $22 \mu \mathrm{g}$ dexamethasone/ $\mu \mathrm{mol}$ total lipid. To determine the influence of serum on the size of PLN-Dex, the nanoemulsions were incubated in PBS buffer, pH: 7.4, supplemented with 50\% foetal calf serum for 24 hours. In this case, the size of PLNDex was $155 \pm 4.3 \mathrm{~nm}$, showing that the exposure of PLNDex to serum does not change significantly their size. An explanation of the stability of PLN-Dex in serum can be the presence of phospholipidic derivatives of PEG on the surface of nanoemulsions that can impede the massive adsorption of serum protein on the surface and the aggregation of nanoparticles. Also, we tested the effect of time storage at $4^{\circ} \mathrm{C}$ and found out that the size of PLN-Dex is not modified significantly after 6 months, when an increase of size with 
$6.95 \pm 2.7 \%$ is observed. The polydispersity index was between 0.08 and 0.18 .

\subsection{Binding and Uptake of P-Selectin Targeted Lipid Nano-} emulsions (PLN) by Activated EA.hy 926 Cells. In preliminary studies, we evaluated, by flow cytometry, the expression of Pselectin on the surface of TNF- $\alpha$ activated human EA.hy926 cells. It was found that $70 \pm 4 \%$ of the activated EC were positive for P-selectin. Therefore, in all further studies, TNF- $\alpha$ activated EA.hy926 cells were employed to assess the binding and uptake of P-selectin targeted nanoemulsion.

The specific binding of PLN to P-selectin expressed on human activated EA.hy926 cells was evaluated by confocal microscopy using fluorescently labeled nanoemulsions. The images obtained revealed that the number of PLN bound on the surface of TNF- $\alpha$ activated EA.hy926 cells was significantly increased in comparison to binding of nontargeted LN (Figure 1(a)).

While specific binding of nanoformulations to the surface of activated EA.hy926 cells is essential to assure a selectivity for the target, the cellular internalization of nanoemulsions could increase the potential therapeutic effect of the encapsulated drug.

The global association (binding and uptake) of Rhodamine-PE labeled nontargeted (LN) and P-selectin targeted lipid nanoemulsions (PLN) to TNF- $\alpha$ activated EA.hy926 cells was monitored by flow cytometry at 2 hours after incubation at $37^{\circ} \mathrm{C}$. The results showed that when TNF$\alpha$ activated EA.hy926 cells were incubated with PLN, the number of Rhodamine-positive cells attained a value of $44 \pm$ $1.4 \%$ above the value obtained in controls in which LN were used (Figure 1(c)).

To test for the specificity of PLN association, the EA.hy926 cells were preincubated with an excess of free peptide before incubation with PLN and LN. This condition significantly reduced the cellular uptake of PLN (39 $\pm 2 \%)$ by TNF- $\alpha$ activated cells (Figures 1(b) and 1(c)), confirming that the binding of PLN to EA.hy926 cells takes place via a Pselectin specific mechanism, mediated by the affinity peptide coupled to the surface of nanoemulsions.

The visualization, by confocal microscopy, of Rhodamine-labeled PLN incubated with TNF- $\alpha$ activated EA.hy926 cells at $37^{\circ} \mathrm{C}$ for different time intervals illustrated a gradual increase of the intracellular fluorescence from $30 \mathrm{~min}$ to 8 hours (Figure 1(d)).

3.3. PLN-Dex Reduces the Gene Expression of Proinflammatory Cytokines in Activated EA.hy926 Cells. We investigated whether the anti-inflammatory activity of dexamethasone is preserved after its efficient encapsulation into nanoemulsions. Thus, the therapeutic effect of dexamethasone, free or loaded into nontargeted LN (LN-Dex) or P-selectin targeted PLN (PLN-Dex) on TNF- $\alpha$ activated EA.hy926 cells, was evaluated by quantifying the mRNA levels of several inflammatory markers such as IL-1 $\beta$, TNF- $\alpha$, IL-6, IL-8, MCP1 , and RANTES. Initially, we found that the incubation of EA.hy 926 cells with TNF- $\alpha$ for 8 hours significantly increased the expression levels of all the proinflammatory cytokines analyzed (Figure 2).
The experiments showed that while the incubation of TNF- $\alpha$ activated EA.hy926 cells with empty PLN did not have any significant effect on the mRNA levels of the inflammatory markers investigated, significantly decreased levels were detected in the case of treatments with free Dex or Dex loaded into nanoemulsions. As expected, free Dex significantly reduced the mRNA expression levels of TNF$\alpha$, IL-6, IL-8, and RANTES in activated EA.hy926 cells, as compared to TNF- $\alpha$ incubated cells lacking Dex treatment (Figure 2). Dex-loaded lipid nanoemulsion (LN-Dex) also reduced the IL- $1 \beta$, TNF- $\alpha$, IL- 8, MCP-1, and RANTES mRNA expression levels by 2.2-, 2.3-, 2.4-, and 3.0-fold, respectively. As shown in Figure 2, free Dex or that loaded into nontargeted nanoemulsions reduced the expression levels of most inflammatory markers evaluated in our study. However, the strongest therapeutic effect was detected when activated cells were treated with P-selectin targeted nanoemulsions loaded with dexamethasone (PLN-Dex) when the mRNA levels of IL-1 $\beta$, TNF- $\alpha$, IL-6, IL- 8 , and RANTES were significantly reduced by 4.4-, 2.5-, 3.9-, 3.7-, and 4.0-fold, respectively.

3.4. PLN-Dex Has a Functional Role in Inhibiting Monocyte Adhesion and Transmigration to/through Activated EA.hy926 Cells. To find out whether, besides reducing the gene expression of several proinflammatory cytokines, the antiinflammatory effect induced by PLN-Dex on TNF- $\alpha$ activated EA.hy926 cells is complemented by a functional effect, that is, inhibition of monocyte adhesion and transmigration through activated EC, it is reported that monocytes adhesion and transmigration into subendothelial space are among the early key events in the pathogenesis of inflammatory diseases [31].

The adhesion of fluorescently labeled monocytes to TNF- $\alpha$ activated EA.hy926 cells was highly increased (3.7fold) compared to the monocyte adhesion to nonactivated EA.hy926 cells (Figure 3(a)). The monocytes adhesion to activated EA.hy926 cells was inhibited by 1.61 -fold in the presence of free Dex at $1 \mu \mathrm{M}$ concentration (Figure $4(\mathrm{a})$ ). The same concentration of Dex incorporated into PLN-Dex induced a significant inhibition of monocyte adhesion (1.8fold). Empty PLN nanoemulsions and LN-Dex also reduced the monocytes adhesion (by about 1.4-fold) but the effect was not statistically significant.

The human monocytes transmigration through EA.hy926 cells monolayer was assessed by the classical transmigration assay using the Boyden chambers as described in Section 2. Activation of EA.hy926 cells with TNF- $\alpha$ significantly increased the monocytes transmigration by 4.1 -fold compared to nonactivated EA.hy926 cells condition (Figure 3(b)).

Coincubation of TNF- $\alpha$ activated EA.hy926 cells with $1 \mu \mathrm{M}$ of PLN-Dex significantly reduced the monocytes transmigration through the EA.hy926 cells monolayer by 2.39-fold. Although free Dex, LN-Dex, and empty PLN slightly decreased the monocytes transmigration, this effect was not statistically significant (Figure 3(b)). While similar concentrations of free dexamethasone were able to reduce the monocytes adhesion to EA.hy926 cells, the monocytes transmigration process could not be reduced by the same 

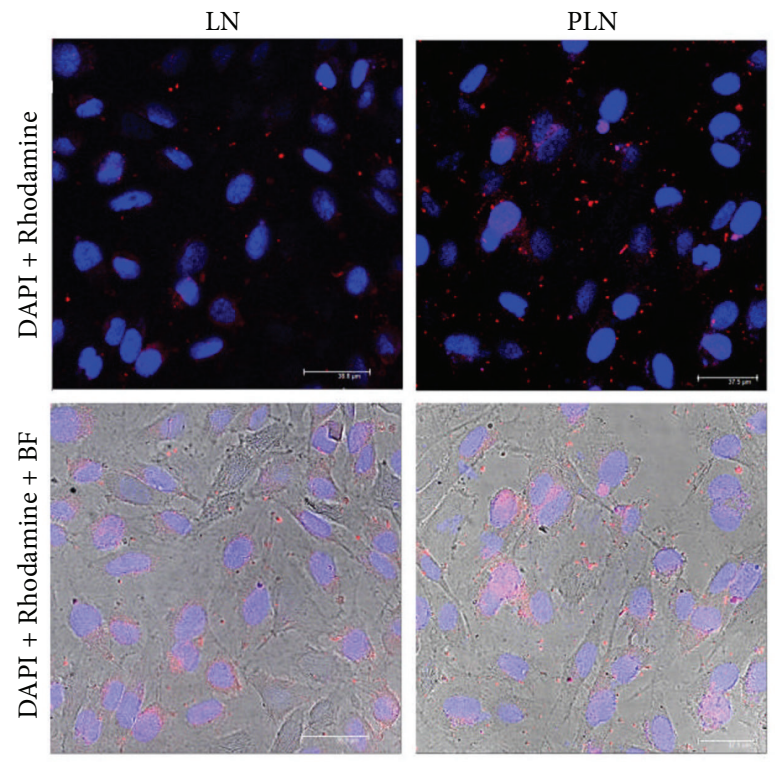

(a)

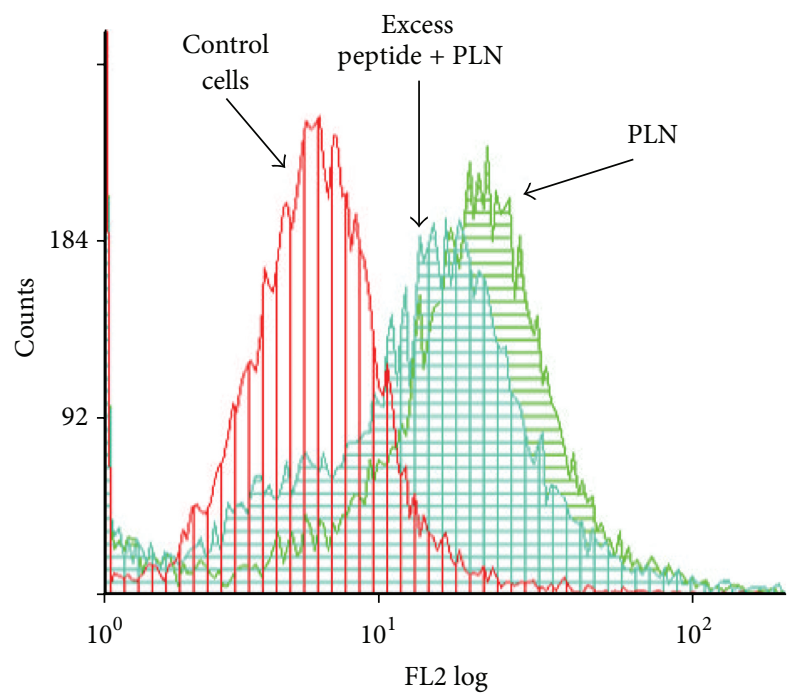

(b)

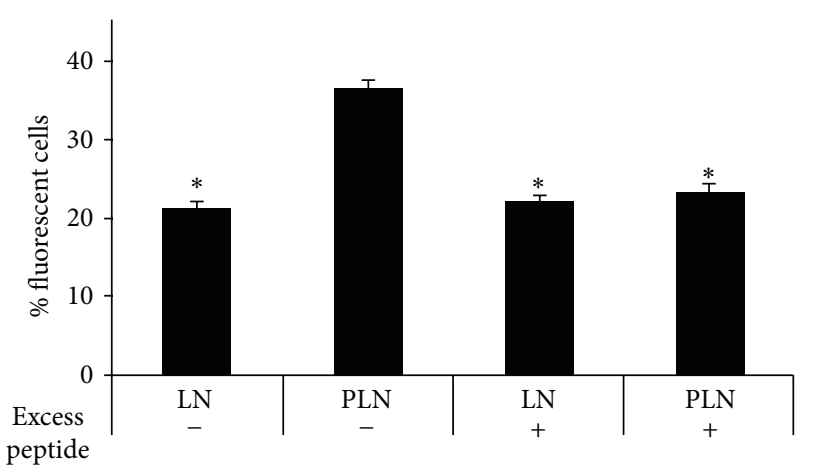

(c)
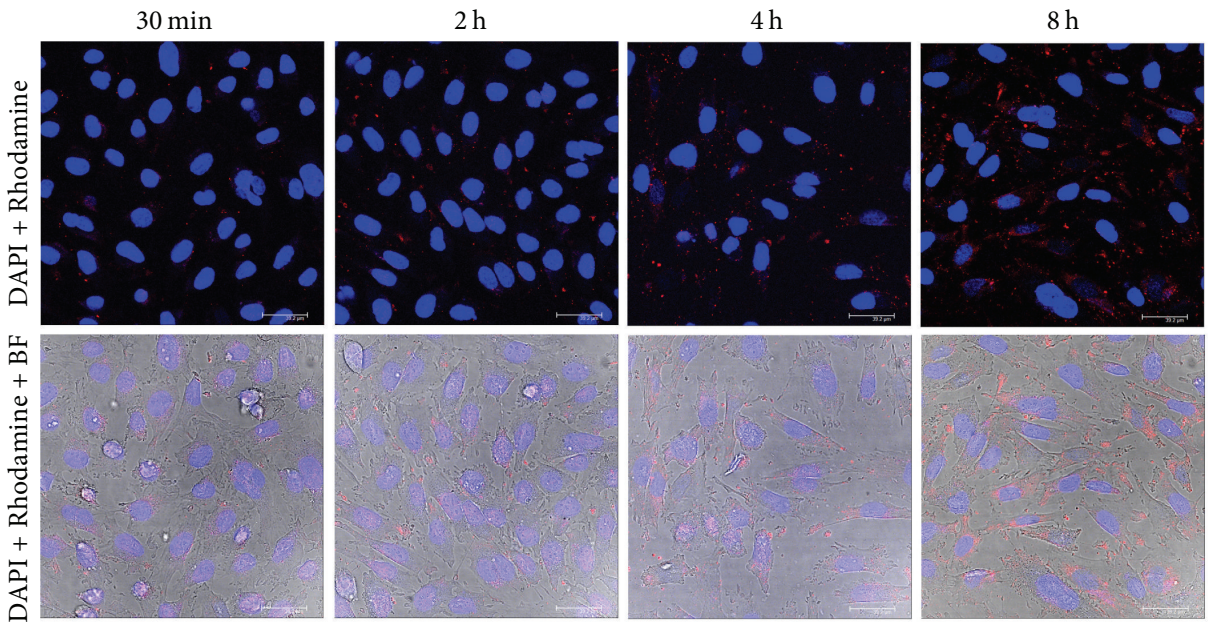

(d)

FIGURE 1: (a) Fluorescence and the overlay between fluorescence and phase contrast images showing the increase in the binding of fluorescently-labeled PLN (red) as compared with nontargeted LN on the surface of paraformaldehyde-fixed, TNF- $\alpha$ activated EC. DAPIstained nuclei appear in blue. Scale bar: $40 \mu \mathrm{m}$. (b) The flow cytometry graphs illustrate the reduced uptake of fluorescently labeled PLN by TNF- $\alpha$ activated EC in the presence of excess of P-selectin binding peptide at 2 hours of incubation at $37^{\circ} \mathrm{C}$. (c) Quantification of cellular uptake of fluorescently labeled LN and PLN in the absence or presence of excess peptide expressed as \% of fluorescently labeled cells. Data represent the mean \pm SD of three independent experiments, ${ }^{*} p<0.05$ versus PLN in the absence of excess peptide. (d) Temporal visualization of PLN internalization by TNF- $\alpha$ activated EC (red), as revealed by confocal microscopy. DAPI-stained nuclei appear in blue. Scale bar: $40 \mu \mathrm{m}$. 

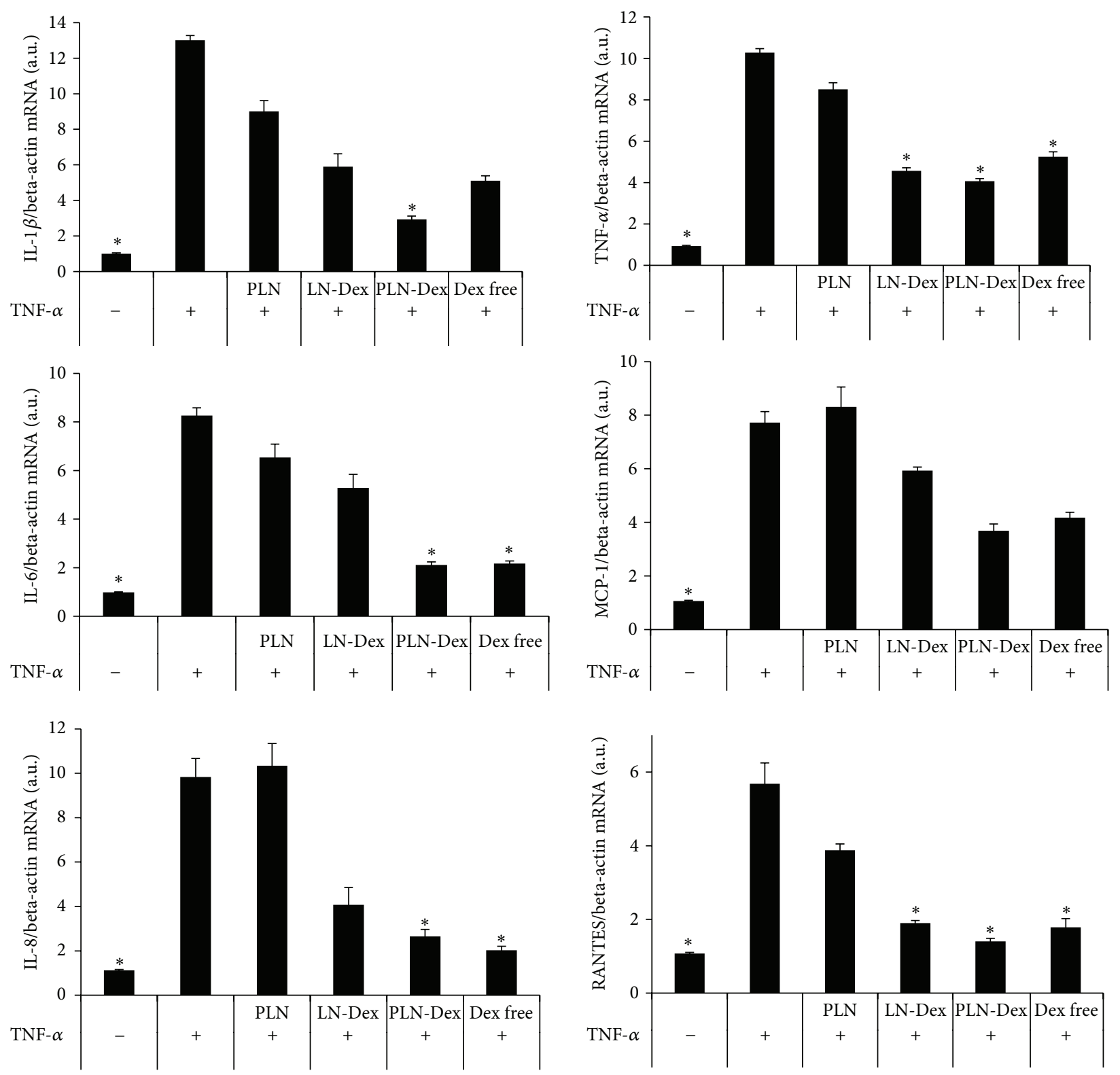

FIGURE 2: The anti-inflammatory effect of free dexamethasone (Dex) or encapsulated in nontargeted (LN-Dex) or P-selectin targeted (PLNDex) lipid nanoemulsions assessed by the expression of mRNA of several proinflammatory molecules in TNF- $\alpha$ activated EC by quantitative RT-PCR and normalized to beta-actin mRNA. Empty PLN were used as control nanoemulsions. Results are expressed as fold induction over the quiescent EC (in the absence of TNF- $\alpha$ ), considered as 1 . The data from 3 up to 6 experiments are expressed as mean \pm SD. ${ }^{*} p<0.05$ significantly different from TNF- $\alpha$ activated EC.

treatment. The different effects of free Dex on the adhesion and transmigration processes can be explained by different incubation times in the two experiments: for monocytes adhesion, the incubation with the EA.hy926 cells was employed for only 30 minutes, while the transmigration experiments were conducted for 16 hours. Therefore, different incubation times of the two experiments can explain the limitations of free dexamethasone in reducing the inflammatory process for a prolonged period of time, as functionalized PLN-Dex proved to be efficient in reducing both adhesion and transmigration of THP monocytes. Although the PLN inhibition of monocytes transmigration was higher than LN (1.54-fold versus 1.15-fold, Figure 4(b)), this difference was not statistically significant.

3.5. Biodistribution Studies of PLN in a Mouse Model of Acute Inflammation. In order to induce acute inflammation in mice, the animals were i.v. injected with LPS $(0.5 \mathrm{mg} / \mathrm{kg})$, and after 4 hours, the Rhodamine-PE labeled PLN or LN were given intravenously. The mice were sacrificed 1 hour after 


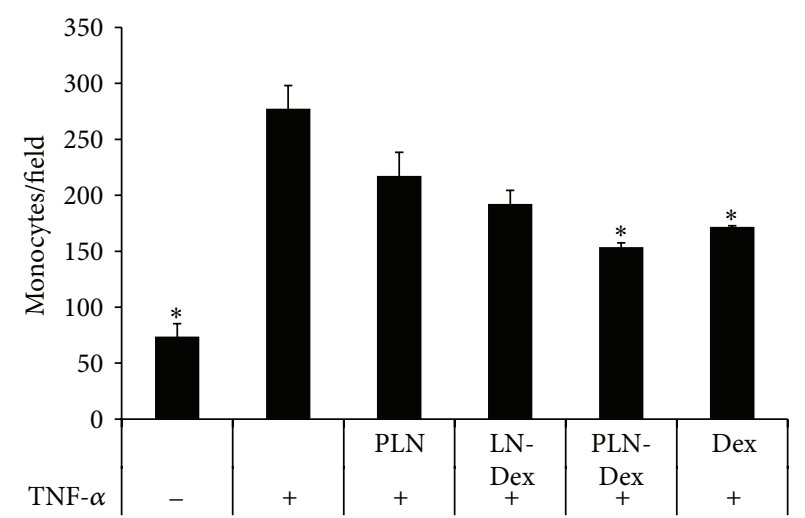

(a)

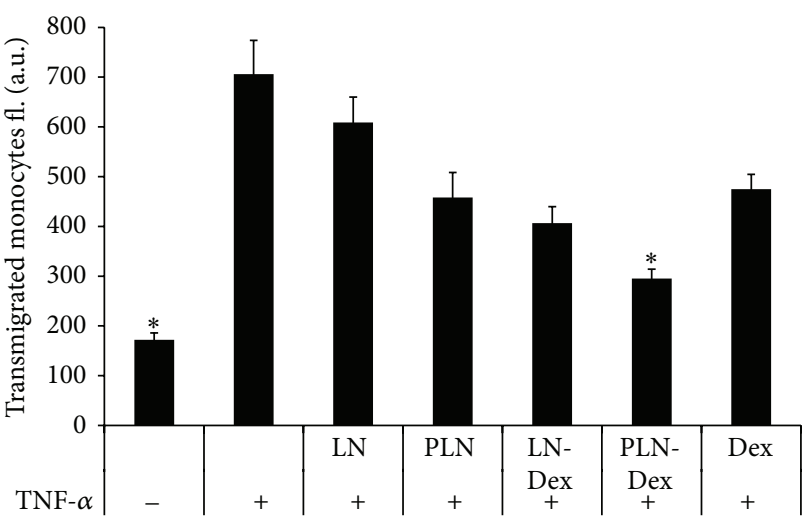

(b)

FIGURE 3: Adhesion (a) and transmigration (b) of monocytes (THP-1 line) to/through TNF- $\alpha$ activated EC in the presence of dexamethasone either free (Dex) or encapsulated in nontargeted (LN-Dex) or P-selectin targeted (PLN-Dex) lipid nanoemulsions. Empty nontargeted (LN) or P-selectin targeted lipid nanoemulsions (PLN) were used as controls. The data are expressed as mean \pm SD of three independent experiments. ${ }^{*} p<0.05$ significantly different from TNF- $\alpha$-activated EC.

the administration of nanoemulsions, the vasculature was washed by heart puncture, and the organs were visualized $e x$ vivo by fluorescent optical imaging employing an IVIS Spectrum system. The biodistribution in organs was quantified for fluorescent radiant efficiency [fluorescence emission radiance per incident excitation intensity $\left.\left(\mathrm{p} / \mathrm{sec} / \mathrm{cm}^{2} / \mathrm{sr}\right) /\left(\mu \mathrm{W} / \mathrm{cm}^{2}\right)\right]$ using region-of-interest (ROI) function of Living Image 4.3.1. software.

In accordance with our previous study of LN biodistribution [25], we observed that the highest accumulation for both LN and PLN occured in the liver of mice injected with PBS as control $\left(928.3 \times 10^{8}\right.$ and $820.6 \times 10^{8}$, resp. $)$ or with LPS $\left(1132 \times 10^{8}\right.$ and $1430 \times 10^{8}$, resp.), with no significant differences between the four groups (Figures 4(a) and 4(b)). Interestingly, PLN accumulation in the lungs of LPS-injected mice was significantly higher than the LN accumulation in the lungs of the same mouse model $\left(74.35 \times 10^{8}\right.$ versus $26.12 \times 10^{8}$ ), while in PBS-injected mice the PLN and LN accumulation in the lungs were similar $\left(15.15 \times 10^{8}\right.$ versus $10.4 \times 10^{8}$ ). For all the other organs analyzed (kidney, spleen, brain, and heart), similar biodistribution was observed for LPS- and PBS-injected mice and no significant differences were observed between PLN and LN, as it can be observed in Figures 4(a) and 4(b).

The significantly increased accumulation of PLN in the lungs can be due to activation of the vascular endothelial cells lining the blood vessels and capillaries in the lungs and overexpression on the plasma membrane of P-selectin. Numerous studies in the literature showed that P-selectin is highly expressed in the mice lungs after LPS administration $[32,33]$. By determining the mRNA expression levels of proinflammatory marker IL- $1 \beta$ in the lysates of lungs, liver, kidneys, and the brain of LPS-injected mice, we observed increased IL$1 \beta$ levels compared to PBS-injected mice, while the highest difference between the two groups was observed in the lungs lysates (Figure 5(a)). This can explain the significantly higher accumulation of PLN in the lungs of LPS-injected mice, as compared to nonfunctionalized LN and to PBSinjected mice.

3.6. Anti-Inflammatory Effects of PLN-Dex in LPS-Injected Mice. The mice were i.v. injected with both LPS $(0.5 \mathrm{mg} / \mathrm{kg})$ and $100 \mu \mathrm{L}$ of free dexamethasone $(1 \mathrm{mg} / \mathrm{kg}$, Dex) or lipid nanoemulsions [PLN-Dex $(0.5 \mathrm{mg} / \mathrm{kg}$ dexamethasone), LNDex $(0.5 \mathrm{mg} / \mathrm{kg}$ dexamethasone), or empty PLN]. After 3 hours, free dexamethasone or lipid nanoemulsions were reinjected into the mice. Anti-inflammatory effects were investigated 24 hours after the LPS administration. The high mRNA levels of the proinflammatory cytokines analyzed (IL$1 \beta$, TNF- $\alpha$, IL-6, and MCP-1) confirmed the strong inflammatory effect induced by LPS in the mice model of acute inflammation (Figure 5(b)). The administration of PLN-Dex to LPS-injected mice significantly reduced the lungs mRNA levels of IL-1 $\beta$, IL-6, and MCP-1 (by 3-fold, 4.4-fold, and 2.37-fold, resp.), compared to untreated LPS-injected mice (Figure 5(b)). The same PLN-Dex treatment decreased the mRNA levels of TNF- $\alpha$ by 2.24-fold, although this reduction was not statistically significant. Interestingly, neither free Dex nor LN-Dex were able to show a significant effect on reducing the expression levels of the four inflammatory markers analyzed. In contrast to the results obtained in vitro on endothelial cells, where free Dex significantly reduced the TNF- $\alpha$ and IL- 6 mRNA levels and LN-Dex decreased the TNF- $\alpha$ levels, an anti-inflammatory effect of the two treatments was not observed in the in vivo experiments. On the contrary, a strong anti-inflammatory effect of PLN-Dex was observed both in vitro and in vivo experiments.

Although not significant, the empty P-selectin targeted PLN slightly decreased the mRNA levels of IL-1 $\beta$, IL-6, and MCP- 1 by $28.3 \%, 25 \%$, and $27.8 \%$, respectively. This is in accordance with numerous preclinical studies, where it was shown that administration of antibodies or P-selectin targeting moieties reduced important inflammatory markers [12-15]. 

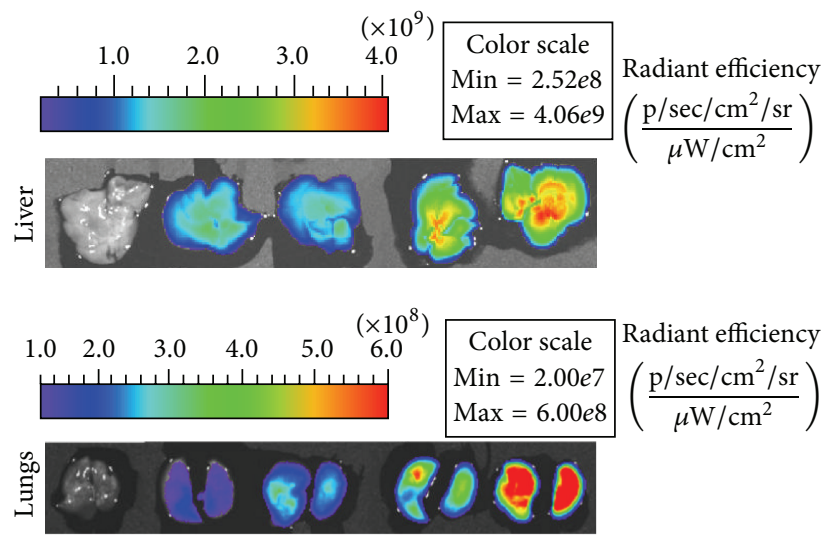

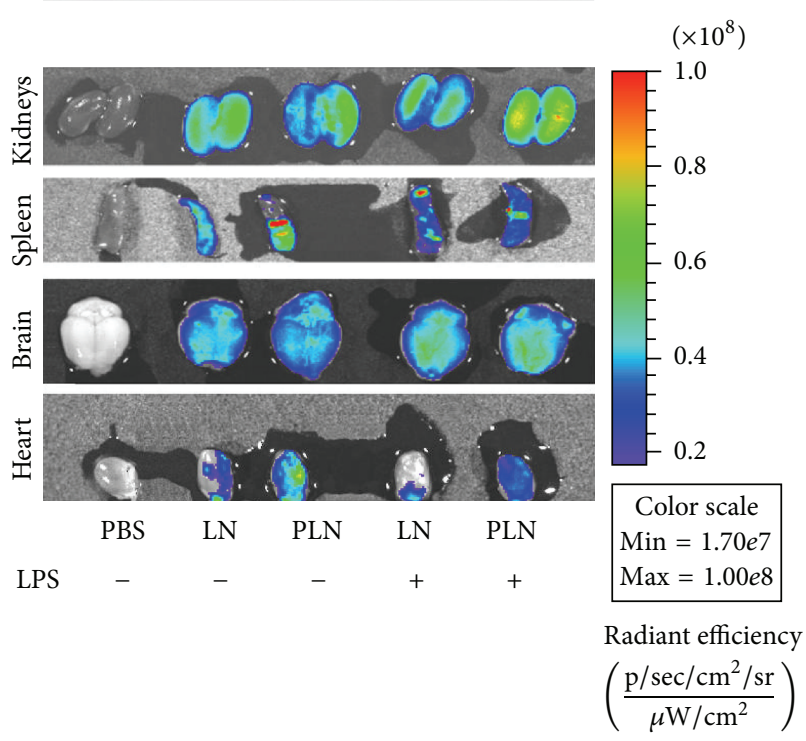

(a)

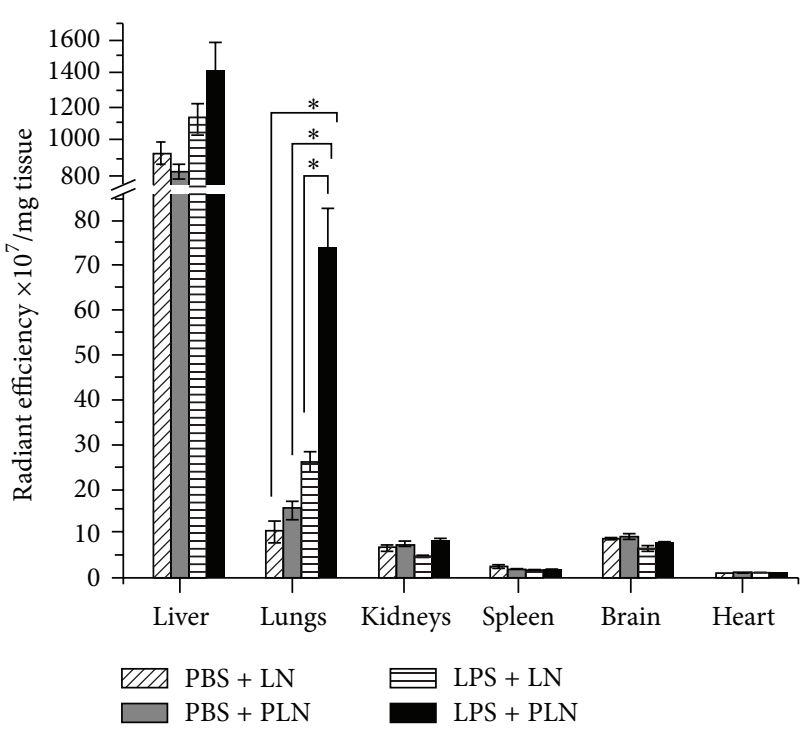

(b)

FIGURE 4: Localization of fluorescently labeled nontargeted or P-selectin targeted lipid nanoemulsions (LN and PLN, resp.) in different organs of C57BL/6 mice at 1 hour after i.v. administration in animals that were previously i.v. injected with PBS (control) or LPS (to induce systemic inflammation). The organs were visualized by an IVIS imaging system Caliper 200 at $\lambda_{\text {ex }}=535 \mathrm{~nm}$ and $\lambda_{\text {em }}=620 \mathrm{~nm}$ (a). The quantification of nanoemulsions accumulation in the investigated organs was done using region-of-interest (ROI) function of Living Image software (b). Values are shown as radiant efficiency per tissue weight (mean $\pm \mathrm{SD}$ ). Three to five animals were used for each experimental group. ${ }^{*} p<0.05$, statistically significant.

\section{Discussions}

Given that the endothelium plays a pivotal role in the development and progression of vascular inflammation and by its strategic position is easily accessible for therapeutic agents given intravenously, the EC represent a rational target for pharmacological intervention. We hypothesize that cell adhesion molecule P-selectin is an appropriate molecular target for nanocarriers directed towards surface of activated endothelium because of its high expression on the plasmalemma of activated EC in both acute inflammatory reactions [34] and chronic inflammation of vascular endothelium overlying atherosclerotic lesions [35]. The expression of P-selectin mRNA in the aortas of ApoE-deficient mice is strongly correlated with the progression of the lesions, suggesting that P-selectin is a good candidate for imaging and targeted therapeutic strategies in atherosclerosis [24].
Compared to E-selectin, the other selectin expressed on EC surface which is internalized via endocytosis and end-up in lysosomes, the P-selectin is internalized by EC utilizing a different pathway, that is, via endosomes, trans-Golgi network (TGN), and storage granules [10, 11]. From early endosomes, the P-selectin is recycled to the TGN with a half time of 20-25 min, six to seven times faster than LDL receptor; hence, the P-selectin expression of the membrane surface is very dynamic [11]. Targeting nanoparticles towards P-selectin may have the advantage of using a route of internalization that avoids lysosomal degradation of the drug entrapped into nanoparticles, leading potentially to a better cytosolic delivery of encapsulated drug (e.g., dexamethasone).

For this study, we developed and characterized lipid nanoemulsions functionalized with a peptide with affinity for P-selectin (PLN) as nanocarriers for the anti-inflammatory drug dexamethasone. We report here that P-selectin targeted 


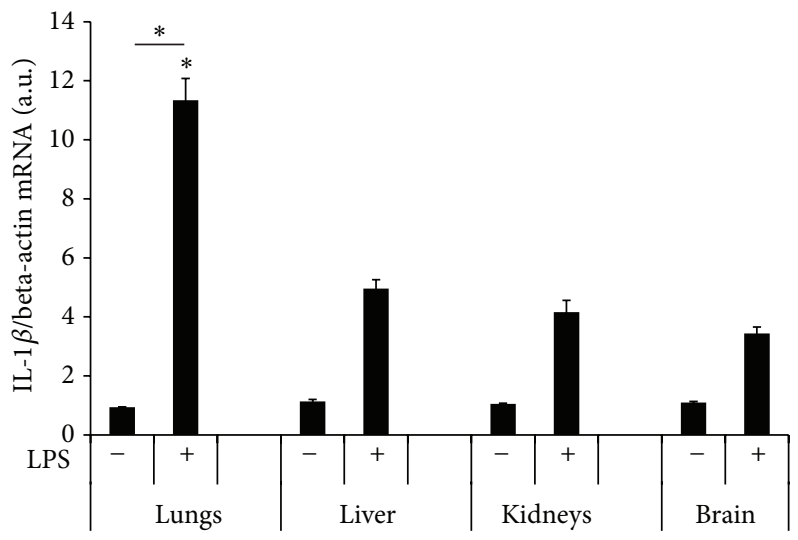

(a)
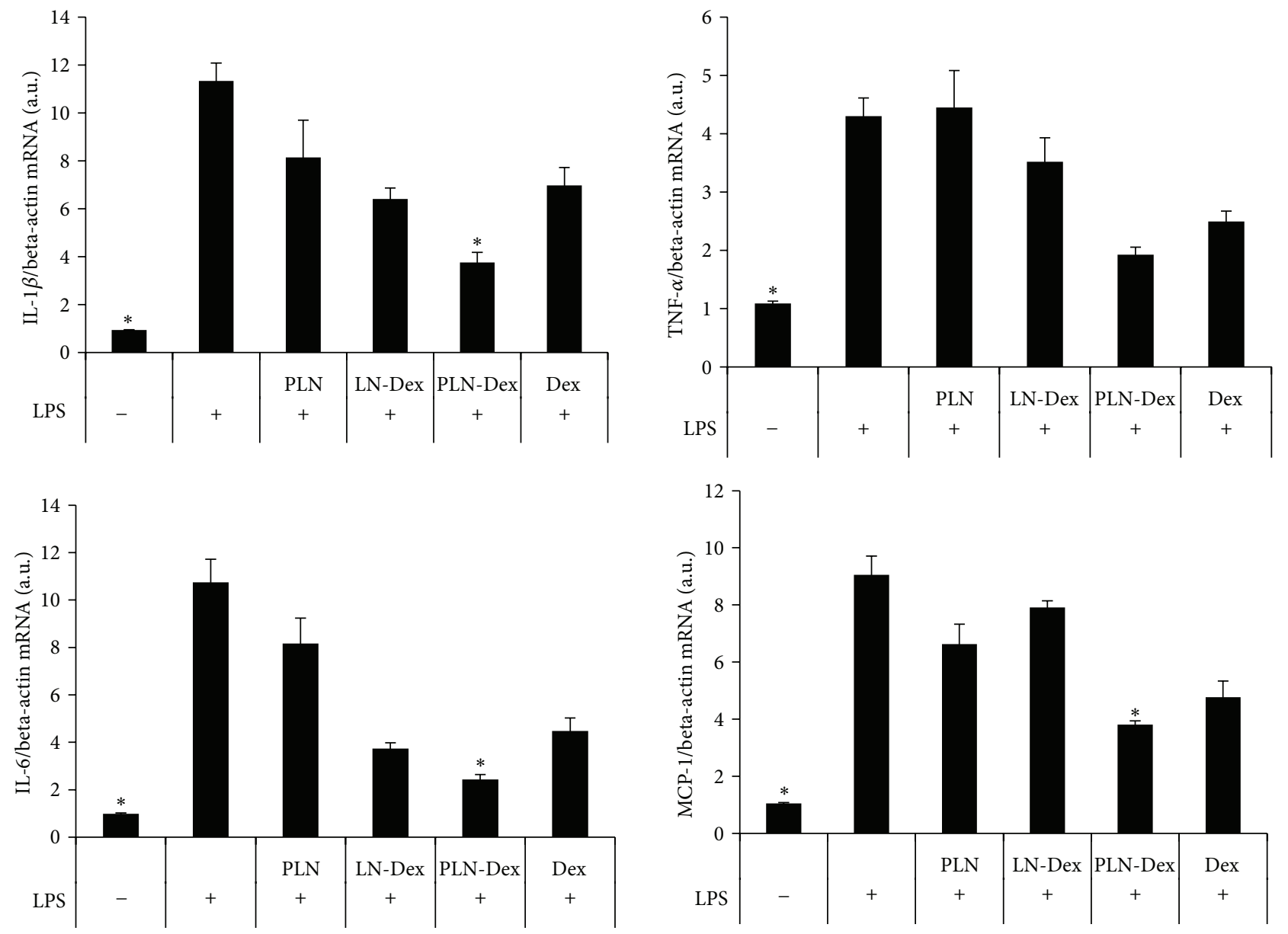

(b)

FIGURE 5: (a) Systemic increase of IL-1 $\beta$ mRNA levels in homogenates of lungs, liver, kidneys, and brain of LPS-treated mice, as determined by RT-PCR and normalized to beta-actin mRNA level. (b) The effect of administration of free dexamethasone (Dex) or encapsulated in nontargeted (LN-Dex) or P-selectin targeted (PLN-Dex) lipid nanoemulsions in LPS-injected mice on mRNA levels of IL-1 $\beta$, TNF- $\alpha$, IL-6, and MCP-1 in lungs homogenates as determined by quantitative RT-PCR and normalized to beta-actin mRNA level. Empty PLN were used as control nanoemulsions. Results are expressed as fold induction over the PBS-treated mice, considered as 1 . The data are expressed as mean $\pm \mathrm{SD} ; n=3-6$ mice per group; ${ }^{*} p<0.05$ statistically significant versus LPS $(+)$. 
nanoemulsions bind and are taken up by activated EC line, EA.hy926 cells, at a higher rate compared to nonfunctionalized LN, attesting that the uptake of PLN is specifically mediated by the peptide coupled on the surface of the nanoemulsions. Moreover, PLN internalization by TNF- $\alpha$ activated EA.hy 926 cells increased gradually for a time period of 8 hours, confirming the presence of the nanoemulsions inside the cytosol. Since dexamethasone mechanism of action is intracellular by binding to the cytosolic glucocorticoid receptor [17], the internalization of P-selectin targeted nanoemulsions could increase the therapeutic effect of Dex incorporated in this formulation, as observed in previous studies $[21,22]$.

Indeed, nanoparticles internalization by EC is dependent on many factors which are relevant in vivo, like shear stress, targeted moiety, endocytosis, and intracellular trafficking [36, 37]. For example, PECAM-1 targeted nanoparticles show different internalization rates dependent on the flow shear stress: acute shear stress, typical for venous vasculature, stimulated the uptake of targeted nanocarriers while chronic shear stress, with the formation of actin stress fibers, decreased their endocytosis [37, 38]. Hence, these factors could impact the PLN-Dex targeting ability and internalization in vivo, and future studies need to be done to decipher these important aspects.

The anti-inflammatory effects of Dex-loaded nanoemulsions were monitored in TNF- $\alpha$ activated EA.hy926 cells. One of the most important groups of inflammatory mediators are the cytokines, and over time some of them have come to be considered as markers of the inflammatory process. In our study, PLN-Dex have significantly decreased the gene expression of key proinflammatory cytokines (e.g., TNF- $\alpha$, IL-1 $\beta$, IL-6, IL-8, MCP-1, and RANTES) in EA.hy926 cells activated with TNF- $\alpha$. This results confirm that the encapsulation of dexamethasone in the nanoemulsions maintained the therapeutic characteristic of the drug, which was potentiated by the targeting approach. The data show a similar reduction of mRNA expression levels of the investigated inflammatory proteins (although not statistically significant in certain cases) for all Dex formulations. This could be explained by the fact that, in cell culture condition, after 8 hours of incubation, the cells can take up free Dex and nontargeted LN-Dex by an unspecific mechanism and the concentration of Dex delivered intracellularly is enough to produce the observed anti-inflammatory effect. On the other hand, in order to increase the efficiency of targeted delivery of Dex in EC by PLN-Dex, attempts should be made to further increase the specificity of targeting by optimizing the density of peptide with P-selectin affinity on the surface of nanoemulsions. The proinflammatory cytokines analyzed are known to increase endothelium inflammation and promote leukocytes recruitment and transmigration in the subendothelial space, two early key events in the pathogenesis of inflammatory diseases [39].

In further experiments, we tested whether the treatment of activated EA.hy926 cells with dexamethasone-loaded nanoemulsions has a functional involvement in monocytes adhesion and transmigration. Incubation of activated EA.hy926 cells with PLN-Dex significantly reduced both monocytes adhesion and transmigration through endothelial cells monolayer. However, similar concentrations of free dexamethasone reduced only the monocytes adhesion and not the transmigration process, a fact that can be explained by the different time points taken for the investigation (30 minutes and 16 hours for adhesion and transmigration experiments, resp.). Hence, the therapeutic effect of free Dex in reducing the cell transmigration inflammatory process was time-limited. This results corroborate well with our previous studies showing that this lipid nanoemulsions formulation has a prolonged time release of encapsulated drug, making them appropriate for a prolonged therapeutic effect [25].

The in vitro results were further confirmed by in vivo studies, using a mouse model of LPS-induced acute inflammation. The organ biodistribution analysis of administered P-selectin-targeted nanoformulations revealed a significantly higher accumulation in the lungs, as compared to nontargeted nanoemulsions. This suggests that LPS induces the activation of the vascular EC lining the blood vessels in the lungs and increases the expression of P-selectin on the plasma membrane. The pulmonary vasculature consists in principal of an extensive capillary network that exhibits $\sim 30 \%$ of the endothelial surface in the body and receives more than $50 \%$ of the entire cardiac output [40]. As a result, agents with an endothelial affinity accumulate in the lungs after intravenous injection, even if their panendothelial target determinants are relatively evenly distributed throughout all types of EC in the body [21, 41].

Indeed, P-selectin is also expressed by activated platelets which play an important role in the inflammatory process. Interestingly, as it was previously established, intravenous administration of LPS does not increase surface expression of P-selectin in mice platelets [42-45]. One possible explanation for this is that platelets do not express CD14 needed for LPS binding to its surface [42]. In accordance with this, in our experiments, we did not find any specific binding of fluorescently labeled PLN to platelets of mice treated with intravenous LPS (data not shown).

In addition, it has been documented that intravenous injection of LPS induces systemic inflammation in all organs but especially in the lungs $[46,47]$. To confirm that intravenous injection of LPS induces an acute inflammation in the main organs of the mice, we determined, by quantitative RT-PCR, the mRNA levels of IL- $1 \beta$ in the lysates of lungs, liver, kidneys, and the brain and found significantly increased levels compared to PBS-injected mice; the highest IL-1 $\beta$ mRNA level was detected in the lungs.

Intravenous administration of $0.5 \mathrm{mg} / \mathrm{kg}$ PLN-Dex had a significantly positive effect in reducing mRNA levels of important proinflammatory cytokines such as IL-1 $\beta$, IL-6, and MCP-1 in the lungs of mice with acute systemic inflammation, while LN-Dex administration had no significant effect. In preliminary studies, we observed that i.v. administration of $0.5 \mathrm{mg} / \mathrm{kg}$ free Dex had no significant therapeutic effect in reducing the proinflammatory cytokines analyzed; hence, we decided to increase the concentration to $1 \mathrm{mg} / \mathrm{kg}$ in our study. The administration of free Dex $(1 \mathrm{mg} / \mathrm{kg})$ had no significant effect on mRNA levels of investigated 
cytokines/chemokines, even though the concentration used was double as compared to the concentration of Dex entrapped into PLN-Dex and LN-Dex $(0.5 \mathrm{mg} / \mathrm{kg})$. Overall, the in vivo results validate the in vitro data obtained on cultured endothelial cells, showing that P-selectin targeted lipid nanoemulsions loaded with dexamethasone have a significant anti-inflammatory effect by reducing the gene expression of proinflammatory molecules. The anti-inflammatory effect observed in PLN-Dex treated mice can be explained by a combined effect of dexamethasone delivered by nanoemulsions, together with the blocking of P-selectin on the surface of EC by targeted nanoemulsions, previously reported to contribute to reducing the inflammatory process $[12,13]$. Our results are in line with the previous studies showing that Dex encapsulated into lysozyme dextran nanogels targeted towards cell adhesion molecule ICAM-1 blocks LPS-induced overexpression of proinflammatory cell adhesion molecules in lungs, when administered i.v. in mice [21].

The approach described in this study may enable future applicability of many potent anti-inflammatory drugs that today do not make it to the clinical trials because of the lack of specificity and the ensuing severe side effects. The local and disease-specific overexpression of P-selectin in inflamed lungs endothelium makes P-selectin an excellent target molecule for site-specific therapy. This strategy may be of clinical relevance for numerous diseases with an inflammatory component where P-selectin is overexpressed, as is the case for atherosclerosis or rheumatoid arthritis.

\section{Conclusions}

The targeted delivery of dexamethasone to activated endothelium by lipid nanoemulsions coupled with a P-selectinspecific peptide as a homing device selectively decreased the expression of proinflammatory genes and reduced the monocytes adhesion and transmigration through endothelial cells monolayer and in vitro in activated cultured endothelial cells and in vivo, in the lungs of a mouse model with acute inflammation. This study demonstrates the potential of cellspecific drug delivery targeted to disease-induced molecules on the endothelial cells' surface as a therapeutic strategy for vascular inflammation.

\section{Ethical Approval}

The experiments on mice had the approval of the Ethics Committee of our institution and were conducted in accordance with the EU guidelines, annex to Directive 86/609, Appendix A of the European Convention for the protection of vertebrate animals used for experimental and other scientific purposes (ETS no. 123), Strasbourg, 2006.

\section{Competing Interests}

The authors report no conflict of interests regarding the publication of this paper.

\section{Acknowledgments}

The authors are indebted to Gabriela Mesca for technical assistance. This work was supported by UEFISCDI (Executive Unit for Funding Education, Research, Development and Innovation) PN II-RU-TE-2014-4-1837 Project and PN-IIID-PCE-2011-3-0928 Project (CARDIOPRO Project ID: 143, ERDF cofinanced investment in RTDI for Competitiveness and by Romanian Academy). This paper is dedicated to the 150th anniversary of the Romanian Academy.

\section{References}

[1] J. P. Cooke, "The endothelium: a new target for therapy," Vascular Medicine, vol. 5, no. 1, pp. 49-53, 2000.

[2] I. Manduteanu and M. Simionescu, "Inflammation in atherosclerosis: a cause or a result of vascular disorders?" Journal of Cellular and Molecular Medicine, vol. 16, no. 9, pp. 1978-1990, 2012.

[3] P. Rajendran, T. Rengarajan, J. Thangavel et al., "The vascular endothelium and human diseases," International Journal of Biological Sciences, vol. 9, no. 10, pp. 1057-1069, 2013.

[4] G. A. Koning, R. M. Schiffelers, and G. Storm, "Endothelial cells at inflammatory sites as target for therapeutic intervention," Endothelium, vol. 9, no. 3, pp. 161-171, 2002.

[5] J. M. Metselaar and G. Storm, "Liposomes in the treatment of inflammatory disorders," Expert Opinion on Drug Delivery, vol. 2, no. 3, pp. 465-476, 2005.

[6] S. Muro and V. R. Muzykantov, "Targeting of antioxidant and anti-thrombotic drugs to endothelial cell adhesion molecules," Current Pharmaceutical Design, vol. 11, no. 18, pp. 2383-2401, 2005.

[7] A. D. Blann, S. K. Nadar, and G. Y. H. Lip, "The adhesion molecule P-selectin and cardiovascular disease," European Heart Journal, vol. 24, no. 24, pp. 2166-2179, 2003.

[8] R. P. McEver, J. H. Beckstead, K. L. Moore, L. Marshall-Carlson, and D. F. Bainton, "GMP-140, a platelet $\alpha$-granule membrane protein, is also synthesized by vascular endothelial cells and is localized in Weibel-Palade bodies," The Journal of Clinical Investigation, vol. 84, no. 1, pp. 92-99, 1989.

[9] J.-G. Geng, M. P. Bevilacqua, K. L. Moore et al., "Rapid neutrophil adhesion to activated endothelium mediated by GMP-140," Nature, vol. 343, no. 6260, pp. 757-760, 1990.

[10] M. Subramaniam, J. A. Koedam, and D. D. Wagner, "Divergent fates of P- and E-selectins after their expression on the plasma membrane," Molecular Biology of the Cell, vol. 4, no. 8, pp. 791801, 1993.

[11] K. S. Straley and S. A. Green, "Rapid transport of internalized P-selectin to late endosomes and the TGN: roles in regulating cell surface expression and recycling to secretory granules," The Journal of Cell Biology, vol. 151, no. 1, pp. 107-116, 2000.

[12] K. Wang, Z. Zhou, X. Zhou, K. Tarakji, E. J. Topol, and A. M. Lincoff, "Prevention of intimal hyperplasia with recombinant soluble P-selectin glycoprotein ligand-immunoglobulin in the porcine coronary artery balloon injury model," Journal of the American College of Cardiology, vol. 38, no. 2, pp. 577-582, 2001.

[13] Z. Zhou, M. S. Penn, F. Forudi et al., "Administration of recombinant P-selectin glycoprotein ligand Fc fusion protein suppresses inflammation and neointimal formation in Zucker diabetic rat model," Arteriosclerosis, Thrombosis, and Vascular Biology, vol. 22, no. 10, pp. 1598-1603, 2002. 
[14] R. M. Nelson, O. Cecconi, W. G. Roberts, A. Aruffo, R. J. Linhardt, and M. P. Bevilacqua, "Heparin oligosaccharides bind L- and P-selectin and inhibit acute inflammation," Blood, vol. 82, no. 11, pp. 3253-3258, 1993.

[15] M. S. Mulligan, J. C. Paulson, S. De Frees, Z.-L. Zheng, J. B. Lowe, and P. A. Ward, "Protective effects of oligosaccharides in P-selectin-dependent lung injury," Nature, vol. 364, no. 6433, pp. 149-151, 1993.

[16] D. Franchimont, E. Louis, W. Dewe et al., "Effects of dexamethasone on the profile of cytokine secretion in human whole blood cell cultures," Regulatory Peptides, vol. 73, no. 1, pp. 59-65, 1998.

[17] T. Rhen and J. A. Cidlowski, "Antiinflammatory action of glucocorticoids-new mechanisms for old drugs," The New England Journal of Medicine, vol. 353, no. 16, pp. 1658-1723, 2005.

[18] D. Liu, A. Ahmet, L. Ward et al., "A practical guide to the monitoring and management of the complications of systemic corticosteroid therapy," Allergy, Asthma and Clinical Immunology, vol. 9, no. 1, article 30, 2013.

[19] A. Gibofsky, "Combination therapy for rheumatoid arthritis in the era of biologicals," HSS Journal, vol. 2, no. 1, pp. 30-41, 2006.

[20] S. A. Ásgeirsdóttir, J. A. A. M. Kamps, H. I. Bakker et al., "Sitespecific inhibition of glomerulonephritis progression by targeted delivery of dexamethasone to glomerular endothelium," Molecular Pharmacology, vol. 72, no. 1, pp. 121-131, 2007.

[21] M. C. C. Ferrer, V. V. Shuvaev, B. J. Zern, R. J. Composto, V. R. Muzykantov, and D. M. Eckmann, "ICAM-1 targeted nanogels loaded with dexamethasone alleviate pulmonary inflammation," PLoS ONE, vol. 9, no. 7, Article ID e102329, 2014.

[22] G. A. Koning, R. M. Schiffelers, M. H. M. Wauben et al., “Targeting of angiogenic endothelial cells at sites of inflammation by dexamethasone phosphate-containing RGD peptide liposomes inhibits experimental arthritis," Arthritis and Rheumatism, vol. 54, no. 4, pp. 1198-1208, 2006.

[23] S. A. Ásgeirsdóttir, P. J. Zwiers, H. W. Morselt et al., "Inhibition of proinflammatory genes in anti-GBM glomerulonephritis by targeted dexamethasone-loaded AbEsel liposomes," American Journal of Physiology-Renal Physiology, vol. 294, no. 3, pp. F554-F561, 2008.

[24] T. J. M. Molenaar, J. Twisk, S. A. M. De Haas et al., "Pselectin as a candidate target in atherosclerosis," Biochemical Pharmacology, vol. 66, no. 5, pp. 859-866, 2003.

[25] V. Simion, D. Stan, C. A. Constantinescu et al., "Conjugation of curcumin-loaded lipid nanoemulsions with cell-penetrating peptides increases their cellular uptake and enhances the antiinflammatory effects in endothelial cells," Journal of Pharmacy and Pharmacology, vol. 68, no. 2, pp. 195-207, 2016.

[26] F. J. Martin and D. Papahadjopoulos, "Irreversible coupling of immunoglobulin fragments to preformed vesicles. An improved method for liposome targeting," Journal of Biological Chemistry, vol. 257, no. 1, pp. 286-288, 1982.

[27] J. Chen, W. T. Dai, Z. M. He et al., "Fabrication and evaluation of curcumin-loaded nanoparticles based on solid lipid as a new type of colloidal drug delivery system," Indian Journal of Pharmaceutical Sciences, vol. 75, no. 2, pp. 178-184, 2013.

[28] M. J. Kang, B. G. Kim, J. Y. Eum et al., "Design of a Pep-1 peptidemodified liposomal nanocarrier system for intracellular drug delivery: conformational characterization and cellular uptake evaluation," Journal of Drug Targeting, vol. 19, no. 7, pp. 497-505, 2011.
[29] C. J. S. Edgell, C. C. McDonald, and J. B. Graham, "Permanent cell line expressing human factor VIII-related antigen established by hybridization," Proceedings of the National Academy of Sciences of the United States of America, vol. 80, no. 12, pp. 3734-3737, 1983.

[30] M. M. Pirvulescu, A.-M. Gan, D. Stan et al., "Curcumin and a Morus alba extract reduce pro-inflammatory effects of resistin in human endothelial cells," Phytotherapy Research, vol. 25, no. 12, pp. 1737-1742, 2011.

[31] R. G. Gerrity, "The role of the monocyte in atherogenesis: I. Transition of blood-borne monocytes into foam cells in fatty lesions," The American Journal of Pathology, vol. 103, no. 2, pp. 181-190, 1981.

[32] W. E. Sanders, R. W. Wilson, C. M. Ballantyne, and A. L. Beaudet, "Molecular cloning and analysis of in vivo expression of murine P-selectin,” Blood, vol. 80, no. 3, pp. 795-800, 1992.

[33] M. Kamochi, F. Kamochi, Y. B. Kim et al., "P-selectin and ICAM-1 mediate endotoxin-induced neutrophil recruitment and injury to the lung and liver," American Journal of Physiology-Lung Cellular and Molecular Physiology, vol. 277, no. 2, part 1, pp. L310-L319, 1999.

[34] K. Ley, "The role of selectins in inflammation and disease," Trends in Molecular Medicine, vol. 9, no. 6, pp. 263-268, 2003.

[35] R. R. Johnson-Tidey, J. L. McGregor, P. R. Taylor, and R. N. Poston, "Increase in the adhesion molecule P-selectin in endothelium overlying atherosclerotic plaques. Coexpression with intercellular adhesion molecule-1," The American Journal of Pathology, vol. 144, no. 5, pp. 952-961, 1994.

[36] S. Muro, X. Cui, C. Gajewski, J.-C. Murciano, V. R. Muzykantov, and M. Koval, "Slow intracellular trafficking of catalase nanoparticles targeted to ICAM-1 protects endothelial cells from oxidative stress," American Journal of Physiology-Cell Physiology, vol. 285, no. 5, pp. C1339-C1347, 2003.

[37] J. Han, V. V. Shuvaev, P. F. Davies, D. M. Eckmann, S. Muro, and V. R. Muzykantov, "Flow shear stress differentially regulates endothelial uptake of nanocarriers targeted to distinct epitopes of PECAM-1," Journal of Controlled Release, vol. 210, pp. 39-47, 2015.

[38] J. Han, B. J. Zern, V. V. Shuvaev, P. F. Davies, S. Muro, and V. Muzykantov, "Acute and chronic shear stress differently regulate endothelial internalization of nanocarriers targeted to plateletendothelial cell adhesion molecule-1," ACS Nano, vol. 6, no. 10, pp. 8824-8836, 2012.

[39] A. H. Sprague and R. A. Khalil, "Inflammatory cytokines in vascular dysfunction and vascular disease," Biochemical Pharmacology, vol. 78, no. 6, pp. 539-552, 2009.

[40] V. R. Muzykantov, Targeted Delivery of Biotherapeutics to the Pulmonary Endothelium, Pulmonary Endothelium: Function in Health and Disease, John Wiley \& Sons, Chichester, UK, 2009.

[41] V. R. Muzykantov, "Targeted drug delivery to endothelial adhesion molecules," ISRN Vascular Medicine, vol. 2013, Article ID 916254, 27 pages, 2013.

[42] J. R. Ward, L. Bingle, H. M. Judge et al., "Agonists of tolllike receptor (TLR) 2 and TLR4 are unable to modulate platelet activation by adenosine diphosphate and platelet activating factor," Thrombosis and Haemostasis, vol. 94, no. 4, pp. 831-838, 2005.

[43] R. E. Rumbaut, R. V. Bellera, J. K. Randhawa et al., "Endotoxin enhances microvascular thrombosis in mouse cremaster venules via a TLR4-dependent, neutrophil-independent mechanism," American Journal of Physiology-Heart and Circulatory Physiology, vol. 290, no. 4, pp. H1671-H1679, 2006. 
[44] G. Andonegui, S. M. Kerfoot, K. McNagny, K. V. J. Ebbert, K. D. Patel, and P. Kubes, "Platelets express functional Toll-like receptor-4,” Blood, vol. 106, no. 7, pp. 2417-2423, 2005.

[45] P. N. Shashkin, G. T. Brown, A. Ghosh, G. K. Marathe, and T. M. McIntyre, "Lipopolysaccharide is a direct agonist for platelet RNA splicing," Journal of Immunology, vol. 181, no. 5, pp. 34953502, 2008.

[46] L. Liaudet, K. G. K. Murthy, J. G. Mabley et al., "Comparison of inflammation, organ damage, and oxidant stress induced by Salmonella enterica serovar muenchen flagellin and serovar enteritidis lipopolysaccharide," Infection and Immunity, vol. 70, no. 1, pp. 192-198, 2002.

[47] E. B. Thorgersen, S. E. Pischke, A. Barratt-Due et al., "Systemic CD14 inhibition attenuates organ inflammation in porcine Escherichia coli sepsis," Infection and Immunity, vol. 81, no. 9, pp. 3173-3181, 2013. 


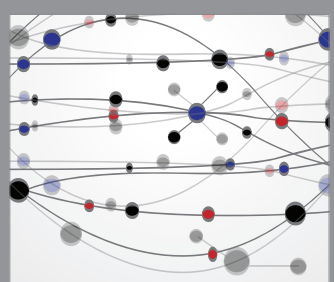

The Scientific World Journal
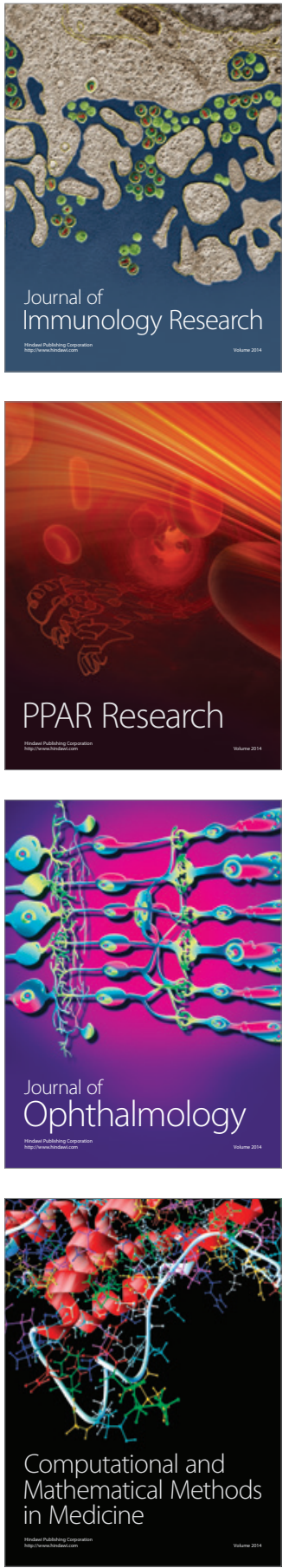

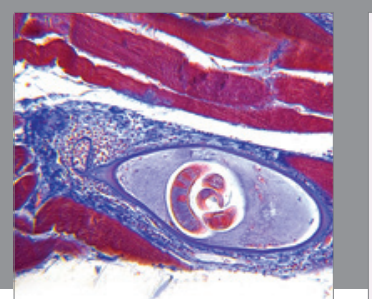

Gastroenterology Research and Practice

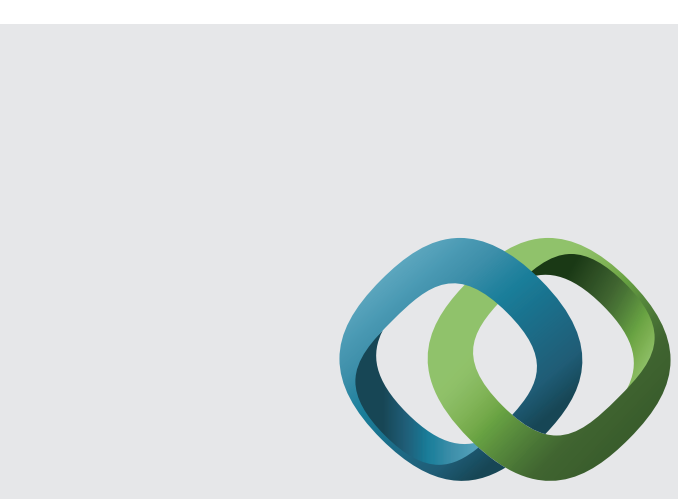

\section{Hindawi}

Submit your manuscripts at

http://www.hindawi.com
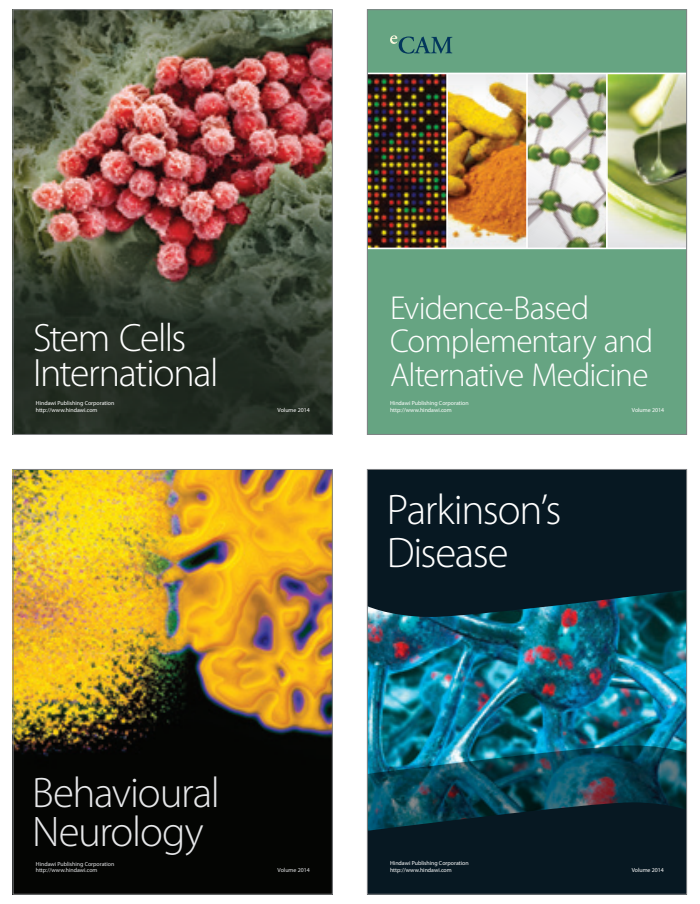
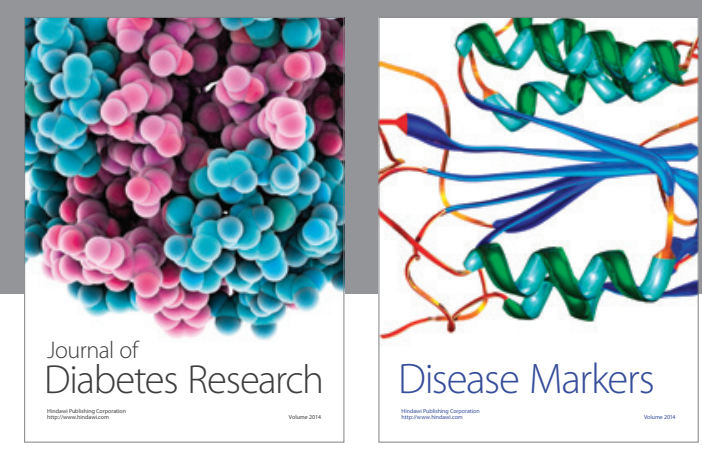

Disease Markers
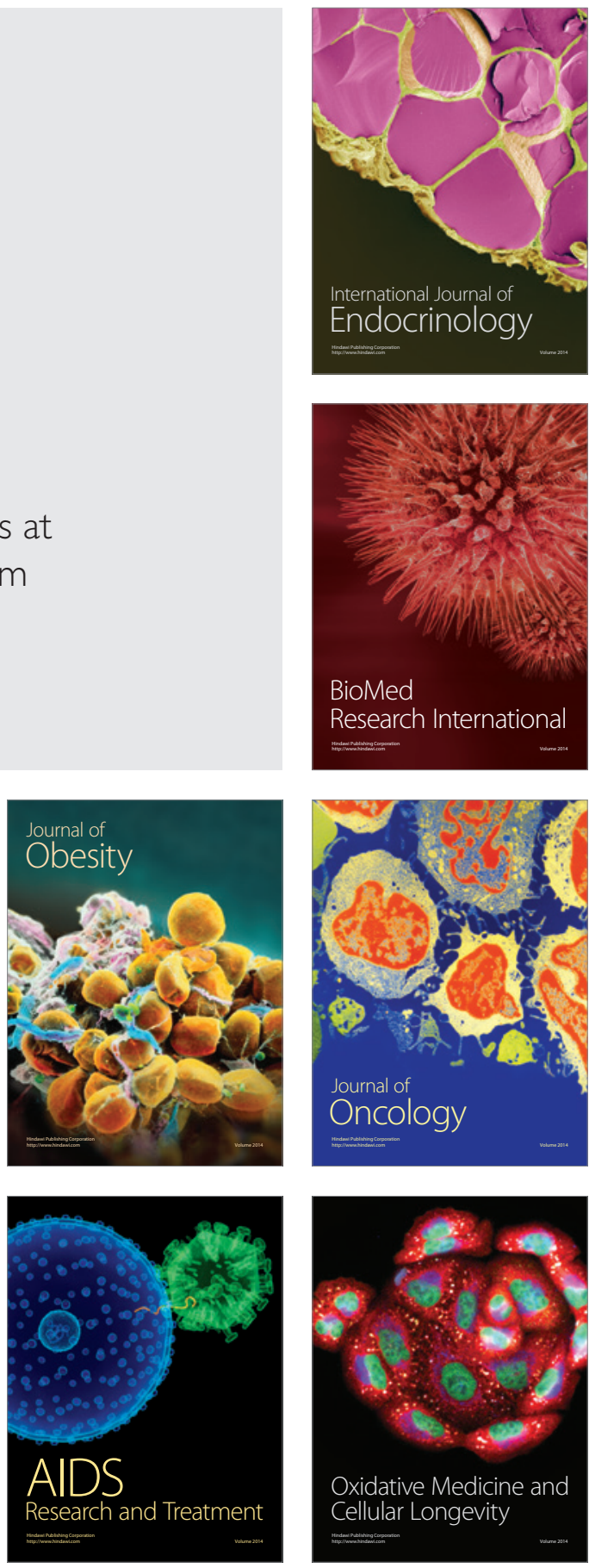